\title{
Antipsychotic agent thioridazine sensitizes renal carcinoma Caki cells to TRAIL-induced apoptosis through reactive oxygen species-mediated inhibition of Akt signaling and downregulation of Mcl-1 and C-FLIP(L)
}

\author{
K-j Min ${ }^{1,4}$, BR Seo ${ }^{1,4}$, YC Bae ${ }^{2}$, YH Yoo ${ }^{*, 3}$ and TK Kwon ${ }^{*, 1}$
}

Thioridazine has been known as an antipsychotic agent, but it also has anticancer activity. However, the effect of thioridazine on tumor necrosis factor-related apoptosis-inducing ligand (TRAIL) sensitization has not yet been studied. Here, we investigated the ability of thioridazine to sensitize TRAIL-mediated apoptosis. Combined treatment with thioridazine and TRAIL markedly induced apoptosis in various human carcinoma cells, including renal carcinoma (Caki, ACHN, and A498), breast carcinoma (MDA-MB231), and glioma (U251MG) cells, but not in normal mouse kidney cells (TMCK-1) and human normal mesangial cells. We found that thioridazine downregulated $c-F L I P(L)$ and Mcl-1 expression at the post-translational level via an increase in proteasome activity. The overexpression of $\mathrm{c}-\mathrm{FLIP}(\mathrm{L})$ and Mcl-1 overcame thioridazine plus TRAIL-induced apoptosis. We further observed that thioridazine inhibited the Akt signaling pathway. In contrast, although other phosphatidylinositol-3-kinase/Akt inhibitors (LY294002 and wortmannin) sensitized TRAIL-mediated apoptosis, C-FLIP(L) and Mcl-1 expressions were not altered. Furthermore, thioridazine increased the production of reactive oxygen species (ROS) in Caki cells, and ROS scavengers ( $\mathrm{N}$-acetylcysteine, glutathione ethyl ester, and trolox) inhibited thioridazine plus TRAIL-induced apoptosis, as well as Akt inhibition and the downregulation of $c-F L I P(L)$ and Mcl-1. Collectively, our study demonstrates that thioridazine enhances TRAIL-mediated apoptosis via the ROS-mediated inhibition of Akt signaling and the downregulation of c-FLIP(L) and Mcl-1 at the post-translational level.

Cell Death and Disease (2014) 5, e1063; doi:10.1038/cddis.2014.35; published online 20 February 2014

Subject Category: Cancer

Thioridazine (10-[2-(1-methyl-2-piperidyl) ethyl]-2-(methylthio) phenothiazine) is a first-generation antipsychotic drug that has been used to treat psychotic disorders, such as psychosis and schizophrenia. ${ }^{1,2}$ Thioridazine also has antimicrobial activity and is thus used as a treatment against drug-resistant organisms, such as Mycobacterium tuberculosis. ${ }^{3,4}$ In addition, thioridazine has anticancer effects, including antiproliferative and antisurvival effects. For example, thioridazine increased apoptosis in cervical and endometrial cancer, ${ }^{5}$ ovarian cancer, ${ }^{6}$ activated B-cell subtype of diffuse B-cell lymphoma, ${ }^{7}$ neuroblastoma and glioma, ${ }^{8}$ leukemia, ${ }^{9}$ and melanoma cells. ${ }^{10}$ One of the molecular mechanisms underlying the anticancer effects of thioridazine might be associated with the inhibition of the phosphatidylinositol-3-kinase (PI3K)/ Akt signaling pathway. ${ }^{5,6}$ The inhibition of mammalian target of rapamycin signaling is also one of the candidate mechanisms of thioridazine. ${ }^{6}$ The inhibition of mitochondrial DNA polymerase and ATP production is involved in the thioridazine-induced apoptosis of leukemic cells. ${ }^{9}$ However, the mechanism that underlies thioridazine-induced apoptosis has not been well documented. Because high concentrations of thioridazine cause side effects, such as dysrhythmia and sudden death, ${ }^{11,12}$ combined treatment with low concentrations of thioridazine plus other anticancer drugs may reduce the occurrence of side effects and improve the drug's anticancer effects.

\footnotetext{
${ }^{1}$ Department of Immunology, School of Medicine, Keimyung University, Daegu 704-701, South Korea; ${ }^{2}$ Department of Anatomy and Neurobiology, School of Dentistry, Kyungpook National University, Daegu 700-412, South Korea and ${ }^{3}$ Department of Anatomy and Cell Biology and Mitochondria Hub Regulation Center, Dong-A University College of Medicine, Busan 602-714, South Korea

${ }^{*}$ Corresponding author: TK Kwon, Department of Immunology, School of Medicine, Keimyung University, 2800 Dalgubeoldaero, Dalseo-Gu, Daegu 704-701, South Korea. Tel: +82 53580 3882; Fax: +82 53580 3795; E-mail: kwontk@dsmc.or.kr

or YH Yoo Department of Anatomy and Cell Biology and Mitochondria Hub Regulation Center, Dong-A University College of Medicine, Busan 602-714, South Korea; Tel: +82 51240 2926; Fax: +82 51241 3767; E-mail: yhyoo@ dau.ac.kr

${ }^{4}$ These authors contributed equally to this work.

Keywords: thioridazine; TRAlL; Akt; Mcl-1; c-FLIP; ROS

Abbreviations: PI3K, Phosphatidylinositol-3-Kinase; TRAIL, Tumor necrosis factor-related apoptosis-inducing ligand; ROS, reactive oxygen species; NAC, N-acetyl-Lcysteine; GEE, glutathione ethyl ester; mTOR, mammalian target of rapamycin; DRs, death receptors; DISC, death-inducing signaling complex; IAPs, inhibitor of apoptosis proteins; CHX, cyclohexamide; PSMA5, 20S proteasome subunit alpha type 5; PSMD4/S5a, 19S proteasome non-ATPase regulatory subunit 4

Received 18.10.13; revised 08.1.14; accepted 09.1.14; Edited by A Stephanou
} 
Tumor necrosis factor-related apoptosis-inducing ligand (TRAIL) activates the extrinsic apoptotic pathway. TRAIL binds to death receptors (DRs; DR4 and DR5) and then recruits caspase- 8 into a death-inducing signaling complex (DISC). The activation of caspase-8 directly activates caspase-3 or induces mitochondria-mediated caspase-3 activation, which results in apoptosis. Previous studies have shown that cancer cells highly express DRs, whereas normal cells highly express the decoy receptors. ${ }^{13}$ Moreover, the level of cellular FLICE-inhibiting protein (c-FLIP $(L)$ ), which inhibits caspase-8 recruitment to DISC, is higher in normal cells than in tumor cells. ${ }^{14}$ Accordingly, TRAIL had been known as a promising anticancer drug. ${ }^{15}$ However, many cancer cells represent resistance to TRAIL-mediated apoptosis via multiple mechanisms. The downregulation of DRs and/or upregulation of antiapoptotic proteins (c-FLIP(L), the Bcl-2 family proteins (Bcl-2, Bcl-xL, and $\mathrm{Mcl}-1$ ) and the inhibitor of apoptosis proteins (IAPs)) have been demonstrated to be associated with TRAIL resistance. ${ }^{16-20}$ Previous studies have shown that TRAILresistant cancer cells can be sensitized by combination treatment. Thus, the development of TRAIL sensitizers is needed to increase sensitivity against TRAIL.

In the present study, we assessed the sensitizing effects of thioridazine on TRAIL-induced apoptosis in human renal carcinoma Caki cells. Combination treatment with TRAIL and thioridazine could facilitate the development of an effective strategy for cancer treatment.

\section{Results}

Thioridazine sensitizes to TRAIL-mediated apoptosis in human renal carcinoma, breast carcinoma, and glioma cells, but not normal cells. Thioridazine has anticancer effects on multiple cancer cells. ${ }^{5-10}$ Therefore, we investigated the ability of thioridazine to sensitize human renal carcinoma Caki cells to TRAIL. To determine whether thioridazine plus TRAIL induce apoptosis, an FACS analysis to measure the DNA content and western blotting to detect the cleavage of PARP, a substrate of caspase-3, were performed. Thioridazine or TRAIL did not affect apoptosis, but a combined treatment with thioridazine plus TRAIL markedly increased the sub-G1 population and PARP cleavage (Figure 1a). In addition, thioridazine plus TRAIL induced chromatin damage in the nuclei (Figure 1b) and cytoplasmic histone-associated DNA fragments (Figure 1c). Combined treatment with thioridazine and TRAIL increased caspase-3 activation (Figure 1d), and z-VAD-fmk (z-VAD), a pan-caspase inhibitor, markedly inhibited thioridazine plus TRAIL-induced apoptosis (Figure 1e, upper panel). The cleavage of PARP and caspase-3 was also blocked by z-VAD treatment (Figure 1e, lower panel). To identify the mechanisms underlying sensitization to TRAIL by thioridazine, we examined the expression levels of apoptosis-related proteins, including the $\mathrm{Bcl}-2$ family, IAP family, constituents of DISC (FADD and cellular FLICE-inhibitory protein (c-FLIP $(L))$, and DRs in thioridazine-treated Caki cells. Thioridazine markedly downregulated c-FLIP(L) and $\mathrm{Mcl}-1$ expression, but the expression of other proteins remained unchanged (Figure 1f). These results indicate that thioridazine sensitizes Caki cells to TRAIL-mediated apoptosis.
Next, we used other human renal carcinoma (ACHN and A498), human breast carcinoma (MDA-MB231), and human glioma (U251MG) cells to investigate the anticancer effect of thioridazine on other carcinoma cells. As shown in Figure 2a, combined treatment with thioridazine plus TRAIL induced apoptosis and PARP cleavage in ACHN, A498, MDA-MB231, and U251MG cells. In contrast, thioridazine plus TRAIL induced neither cellular shrinkage nor apoptosis in normal cells (mouse kidney cells (TMCK-1) and human mesangial cells), whereas cellular shrinkage and blebbing was detected in Caki cells (Figure 2b). Furthermore, thioridazine induced the downregulation of $\mathrm{c}$-FLIP $(\mathrm{L})$ and $\mathrm{Mcl}-1$ expression in carcinoma cells, but not in normal cells (Figure 2c). These data indicate that thioridazine can sensitize cancer cells other than Caki cells to TRAIL.

c-FLIP(L) and Mcl-1 are downregulated at the post-translational levels in thioridazine-treated Caki cells. Because thioridazine induced the downregulation of c-FLIP $(\mathrm{L})$ and $\mathrm{Mcl}-1$ expression (Figure 1f), we investigated how thioridazine inhibits c-FLIP(L) and $\mathrm{Mcl}-1$ protein expression. Thioridazine inhibited c-FLIP(L) and Mcl-1 expression within $3 \mathrm{~h}$ and then gradually reduced their levels further until the 24-h time point (Figure 3a, upper panel). However, we found that the mRNA expressions of $c$-FLIP $(L)$ and $M c l-1$ were not changed in thioridazine-treated Caki cells (Figure 3a, lower panel). Therefore, we examined the ability of thioridazine to modulate the protein stabilities of c-FLIP(L) and $\mathrm{Mcl}-1$. Caki cells were treated with cyclohexamide (CHX), an inhibitor of de novo protein synthesis, or $\mathrm{CHX}$ plus thioridazine. Although treatment with $\mathrm{CHX}$ alone downregulated $\mathrm{c}-\mathrm{FLIP}(\mathrm{L})$ and $\mathrm{Mcl}-1$ expressions, combined treatment with $\mathrm{CHX}$ and thioridazine more markedly reduced c-FLIP(L) and Mcl-1 expressions (Figure 3b). These data suggested that thioridazine downregulated both c-FLIP(L) and $\mathrm{Mcl}-1$ expressions at the post-translational level.

We treated c-FLIP(L)- or Mcl-1-overexpressing Caki cells with TRAIL in the absence or presence of thioridazine. Although combined treatment with thioridazine plus TRAIL increased the sub-G1 population and induced PARP cleavage in Caki/vector cells, thioridazine plus TRAIL did not induce apoptosis in Caki/c-FLIP(L) and Caki/Mcl-1 cells (Figures 3c and $d$ ). These data indicate that the downregulation of c-FLIP $(\mathrm{L})$ and $\mathrm{Mcl}-1$ is important to thioridazine-mediated TRAIL sensitization.

Thioridazine-induced proteasome activity is associated with downregulation of $\mathrm{c}-\mathrm{FLIP}(\mathrm{L})$ and $\mathrm{Mcl}-1$ expression. Previous studies reported that $c-F L I P(L)$ and $\mathrm{Mcl}-1$ are degraded by the proteasome-ubiquitin system. ${ }^{21,22}$ Therefore, we investigated whether the downregulation of c-FLIP $(L)$ and $\mathrm{Mcl}-1$ is associated with proteasome activity. First, we examined the ability of proteasome inhibitors (MG132 and lactacystin) to reverse the thioridazine-mediated downregulation of $\mathrm{C}-\mathrm{FLIP}(\mathrm{L})$ and $\mathrm{Mcl}-1$ expression. As shown in Figure 4a, proteasome inhibitors blocked the downregulation of c-FLIP(L) and Mcl-1 expression. Next, we measured the chymotrypsin-like activity of proteasome with Suc-Leu-LeuVal-Tyr-AMC as the proteasome substrate to investigate the ability of thioridazine to increase proteasome activity. 


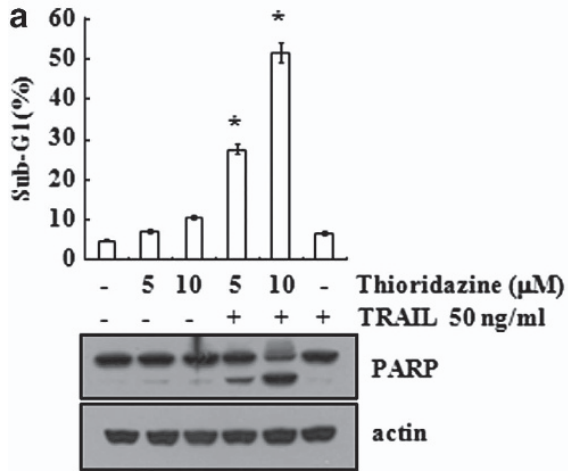

d

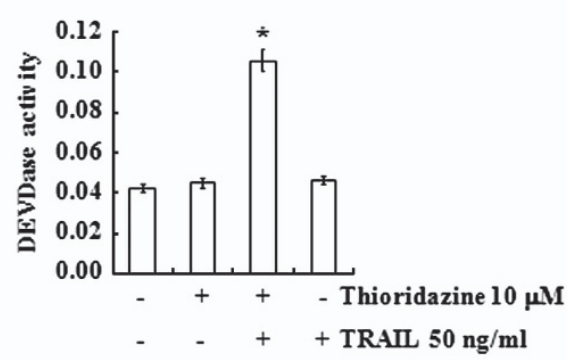

b

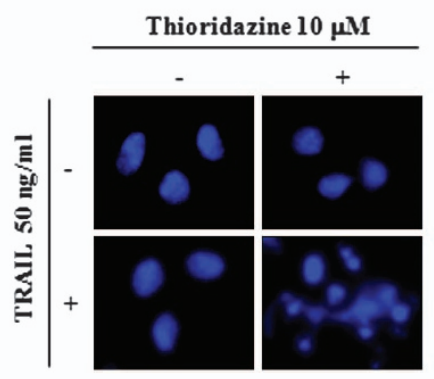

e
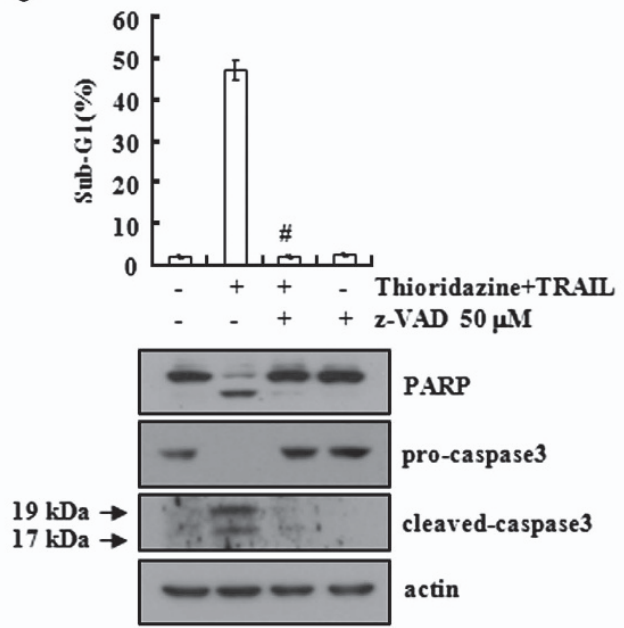
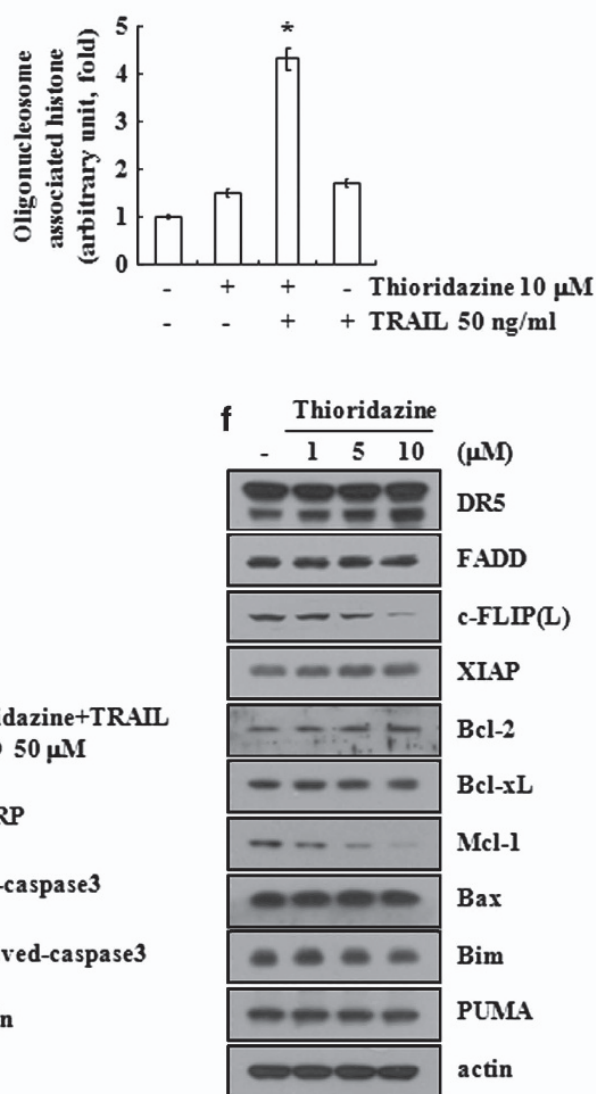

Figure 1 Thioridazine sensitizes Caki cells to TRAIL-mediated apoptosis. (a) Caki cells were treated with $50 \mathrm{ng} / \mathrm{ml}$ TRAIL in the presence or absence of the indicated concentrations of thioridazine for $24 \mathrm{~h}$. The sub-G1 fraction was measured by flow cytometry as an indicator of the level of apoptosis. The protein expression levels of PARP and actin were determined by western blotting. The level of actin was used as a loading control. (b-d) Caki cells were treated with $50 \mathrm{ng} / \mathrm{ml}$ TRAlL in the presence or absence of $10 \mu \mathrm{M}$ thioridazine for $24 \mathrm{~h}$. The condensation and fragmentation of the nuclei were detected by $4^{\prime}, 6^{\prime}$-diamidino-2-phenylindole staining (b). The cytoplasmic histoneassociated DNA fragments were determined by a DNA fragmentation detection kit (c). Caspase activities were determined with colorimetric assays using caspase-3 (DEVDase) assay kits (d). (e) Caki cells were treated with $10 \mu \mathrm{M}$ thioridazine plus $50 \mathrm{ng} / \mathrm{ml}$ TRAIL for $24 \mathrm{~h}$ in the presence or absence of $50 \mu \mathrm{M} z-\mathrm{VAD}$-fmk (z-VAD). The subG1 fraction was measured by flow cytometry. The protein expression levels of PARP, procaspase-3, cleaved caspase-3, and actin were determined by western blotting. The level of actin was used as a loading control. (f) Caki cells were treated with the indicated concentrations of thioridazine for $24 \mathrm{~h}$. The protein expression levels of DR5, FADD, c-FLIP(L), XIAP, Bcl-2, Bcl-xL, Mcl-1, Bax, Bim, Puma, and actin were determined by western blotting. The level of actin was used as a loading control. The values in a, c, d, and e represent the mean \pm S.D. from three independent samples. ${ }^{*} P<0.001$ compared with the thioridazine treatment alone. ${ }^{\#} P<0.001$ compared with the co-treatment of thioridazine and TRAIL. The data represent three independent experiments

As expected, thioridazine increased the chymotrypsin-like activity of the proteasome within $12 \mathrm{~h}$ (Figure $4 \mathrm{~b}$ ). We used the proteasome sensor vector, ZsProSensor-1, to confirm the induction of proteasome activity by thioridazine. The vector encodes a destabilized green fluorescence protein (ZsGreen), which is rapidly degraded by proteasomes. For example, when proteasomes are inhibited, the fluorescent protein accumulates, which allows green fluorescence to be detected by fluorescence microscopy. Importantly, thioridazine decreased green fluorescence, whereas MG132 increased green fluorescence (Figure 4c). We further examined the ability of thioridazine to modulate the protein expression of two critical proteasome subunits: 20 S proteasome subunit alpha type 5 (PSMA5) and 19S proteasome non-ATPase regulatory subunit 4 (PSMD4/S5a). ${ }^{23}$ However, the increase in the proteasome activity was not associated with PSMA5 and PSMD4/S5a expression in thioridazinetreated Caki cells. Next, we investigated the importance of the downregulation of $\mathrm{c}-\mathrm{FLIP}(\mathrm{L})$ and $\mathrm{Mcl}-1$ due to proteasome activation to thioridazine plus TRAIL-mediated apoptosis. When proteasome inhibitors (MG132 and lactacystin) reversed the downregulation of $c-F L I P(L)$ and $M c l-1$, the subG1 population and PARP cleavage were markedly inhibited in thioridazine plus TRAIL-treated cells (Figure 4e). These data suggest that the downregulation of $\mathrm{c}-\mathrm{FLIP}(\mathrm{L})$ and $\mathrm{Mcl}-1$ expression due to the induction of proteasome activity is critical in thioridazine plus TRAIL-mediated apoptosis.

Inhibition of Akt signaling is involved in thioridazinemediated TRAIL sensitization. Thioridazine has been known to exert anticancer effects via the inhibition of the PI3K/Akt signaling pathways. ${ }^{5,6}$ To examine the involvement of the PI3K/Akt pathway in thioridazine-mediated TRAIL sensitization, we tested the effect of PI3K/Akt inhibitors (LY294002 and wortmannin) on C-FLIP(L) and Mcl-1 expression. Although LY294002 and wortmannin, similar to 

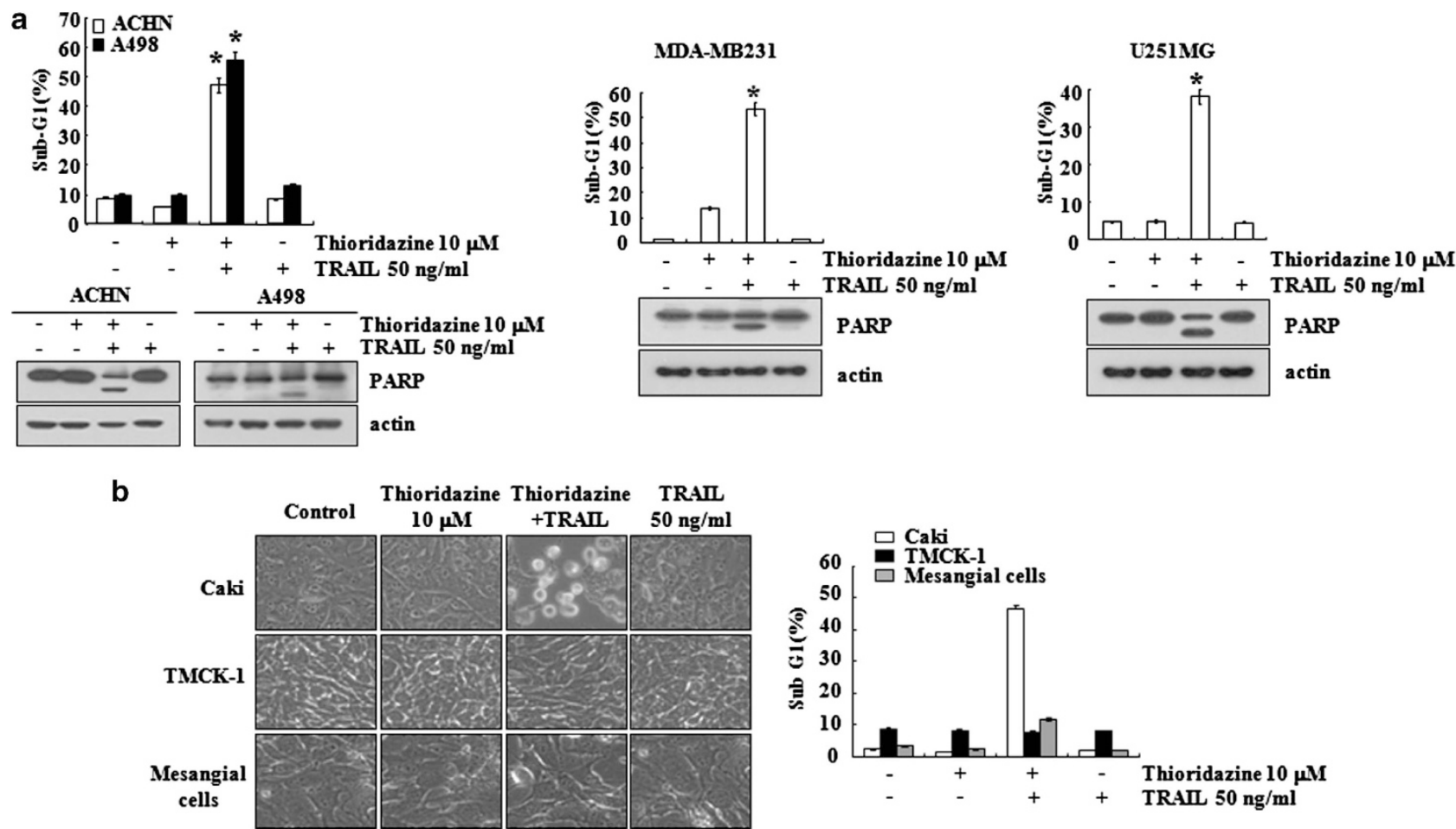

C
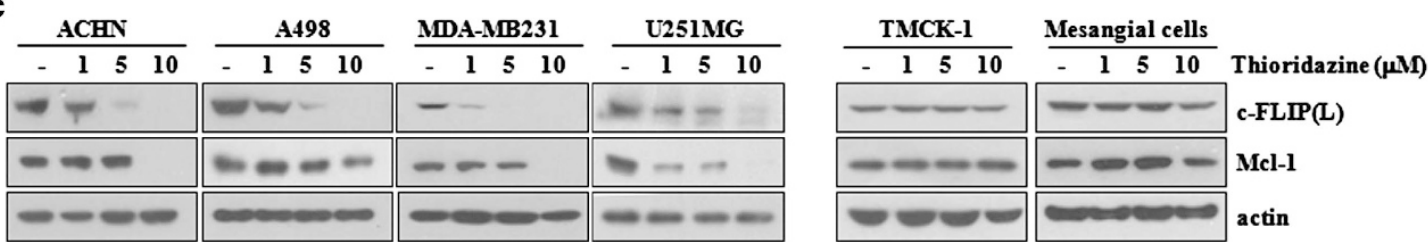

Figure 2 The effects of co-treatment with thioridazine plus TRAIL on apoptosis in other carcinoma cell lines, and normal cells. (a) Renal carcinoma (ACHN and A498), breast carcinoma (MDA-MB231), and glioma (U251MG) cells were treated with $50 \mathrm{ng} / \mathrm{ml}$ TRAlL in the presence or absence of $10 \mu \mathrm{M}$ thioridazine for $24 \mathrm{~h}$. The level of apoptosis was measured by the sub-G1 fraction using flow cytometry. The protein expression levels of PARP and actin were determined by western blotting. The level of actin was used as a loading control. (b) Caki, TMCK-1, and mesangial cells were treated with $50 \mathrm{ng} / \mathrm{ml}$ TRAIL in the presence or absence of $10 \mu \mathrm{M}$ thioridazine for $24 \mathrm{~h}$. The cell morphology was examined using interference light microscopy (left panel). The level of apoptosis was analyzed by measuring the sub-G1 fraction by flow cytometry (right panel). (c) Renal carcinoma (ACHN and A498), breast carcinoma (MDA-MB231), and glioma (U251MG) cells were treated with the indicated concentrations of thioridazine for $24 \mathrm{~h}$. The protein expression levels of c-FLIP(L), Mcl-1, and actin were determined by western blotting. The level of actin was used as a loading control. The values in (a and $\mathbf{b})$ represent the mean \pm S.D. from three independent samples. ${ }^{*} P<0.001$ compared with the thioridazine treatment alone. The data represent three independent experiments

thioridazine, markedly inhibited Akt phosphorylation within $3 \mathrm{~h}, \mathrm{LY} 294002$ and wortmannin did not reduce the c-FLIP(L) and $\mathrm{Mcl}-1$ expression levels (Figure $5 \mathrm{a}$ ). The present study demonstrates that thioridazine, unlike LY294002 and wortmannin, exhibits an additional activity in downregulating c-FLIP(L) and Mcl-1 expression beyond the inhibition of Akt signaling. Therefore, we hypothesized that thioridazine could be a stronger TRAIL sensitizer than LY294002 and wortmannin. Our data indicated that the increased sensitivity to TRAIL-mediated apoptosis was most pronounced in thioridazine-treated cells (Figure $5 b$ ). These data collectively suggest that thioridazine, via the downregulation of c-FLIP $(L)$ and $\mathrm{Mcl}-1$ expression, could serve as a more effective agent to induce TRAIL-mediated apoptosis.

Thioridazine increased ROS production. The effect of thioridazine on reactive oxygen species (ROS) production is controversial. Thioridazine increased the levels of ROS in myelin and mitochondria in rats, ${ }^{24}$ but also had antioxidant activity via an interaction with the inner membrane of mitochondria in rat liver mitochondria. ${ }^{25}$ We examined the ability of thioridazine to increase ROS production in Caki cells. As shown in Figures $6 a$ and b, thioridazine markedly induced intracellular ROS production, and pretreatment with ROS scavengers ( $N$-acetyl-L-cysteine (NAC), glutathione ethyl ester (GEE), and trolox) inhibited the increase in the sub-G1 population and PARP cleavage in thioridazine plus TRAIL-treated cells. Furthermore, all ROS scavengers reversed the downregulation of $c-F L I P(L)$ and $M c l-1$ and prevented the inhibition of Akt phosphorylation in thioridazine plus TRAIL-mediated cells. As shown in Figures 3 and 4, both c-FLIP $(\mathrm{L})$ and $\mathrm{Mcl}-1$ expression were downregulated at the post-translational levels via a proteasome degradation pathway. Therefore, Caki cells were pretreated with ROS scavengers followed by the addition of thioridazine to further examine the association between ROS and the induction of 
a
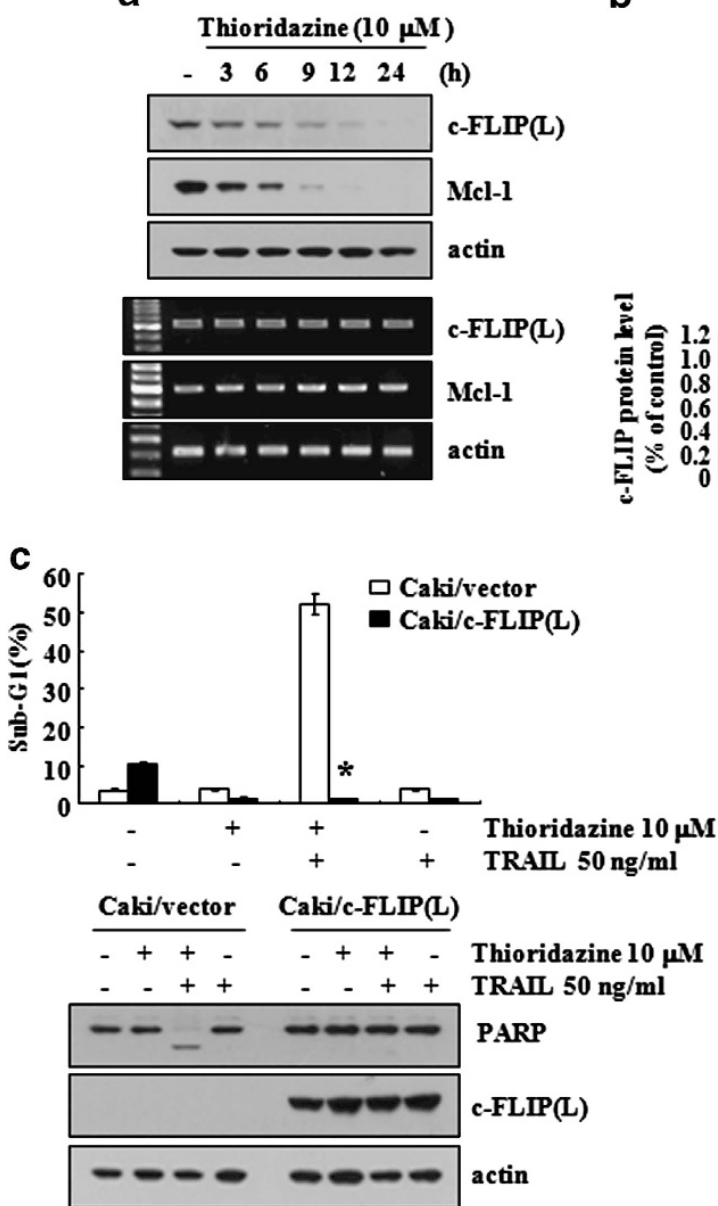

b
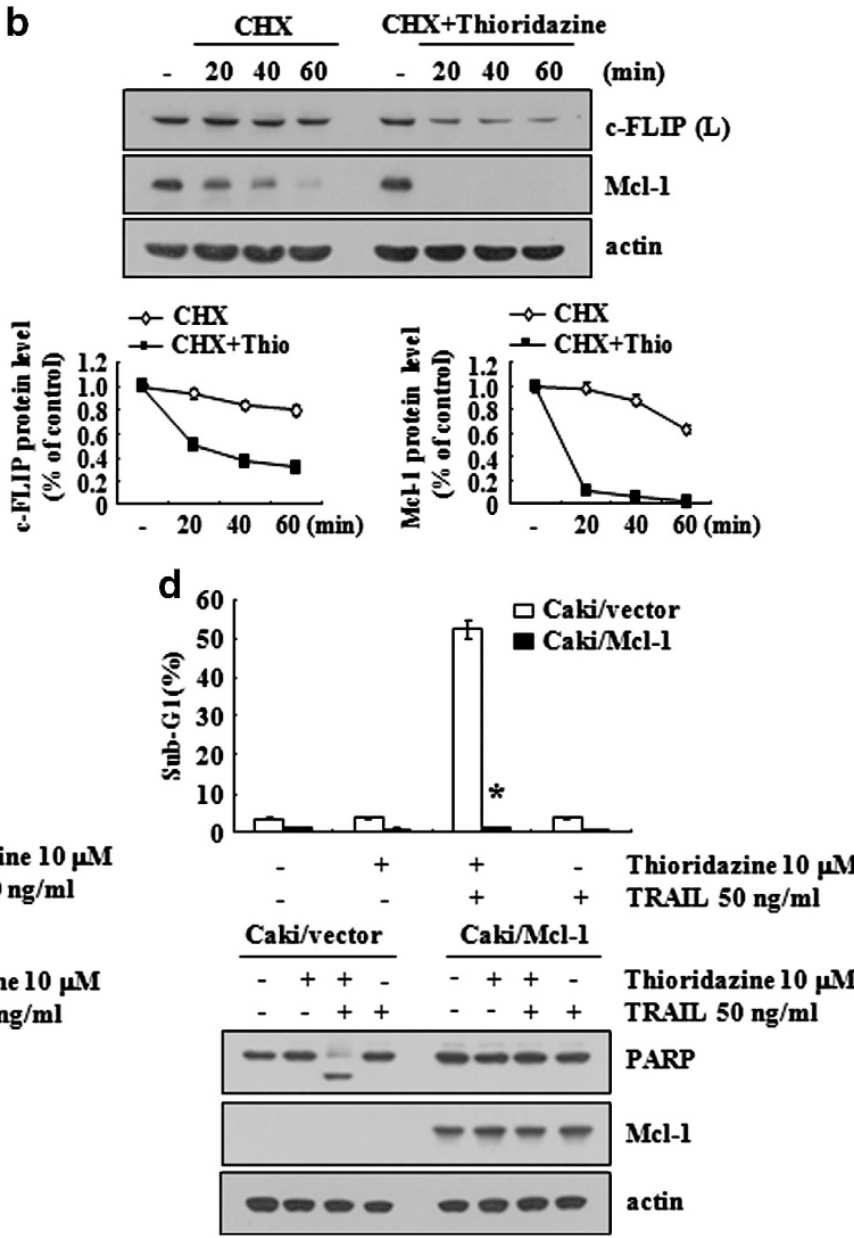

Figure 3 The downregulation of $\mathrm{c}-\mathrm{FLIP}(\mathrm{L})$ and Mcl-1 by thioridazine is associated with the induction of TRAIL-mediated apoptosis. (a) Caki cells were treated with $10 \mu \mathrm{M}$ thioridazine for the indicated time periods. (b) Caki cells were treated with or without $10 \mu \mathrm{M}$ thioridazine (Thio) in the presence of $\mathrm{CHX}(20 \mu \mathrm{g} / \mathrm{ml})$ for the indicated time periods. (c and d) Vector cells (Caki/vector), c-FLIP(L)-overexpressed cells (Caki/cFLIP (L)), and Mcl-1-overexpressed cells (Caki/Mcl-1) were treated with $50 \mathrm{ng} / \mathrm{ml}$ TRAIL in the presence or absence of $10 \mu \mathrm{M}$ thioridazine for $24 \mathrm{~h}$. The level of apoptosis was analyzed by the sub-G1 fraction using flow cytometry. The protein and mRNA expression levels of c-FLIP(L) and/or Mcl-1 were determined by western blotting (a, b, $\mathbf{c}$, and $\mathbf{d})$ and RT-PCR (a), respectively. The level of actin was used as a loading control. The band intensities of c-FLIP(L) and Mcl-1 protein were measured using the public domain JAVA image-processing program ImageJ (b, lower panel). ${ }^{*} P<0.001$ compared with the thioridazine plus TRAIL-treated Caki/vector cells. The data represent three independent experiments

thioridazine-mediated proteasome activity. As predicted, ROS scavengers markedly inhibited proteasome activity. These data indicate that thioridazine downregulated c-FLIP(L) and Mcl-1 expression via an increase in ROS-mediated proteasome activity.

Taken together, our results demonstrate that thioridazine sensitizes cells to TRAIL-induced apoptosis via the ROS-mediated inhibition of Akt signaling and downregulation of $\mathrm{Mcl}-1$ and $\mathrm{c}-\mathrm{FLIP}(\mathrm{L})$ at the post-translational levels.

\section{Discussion}

In this study, we demonstrated the mechanism that underlies the sensitization to TRAIL-mediated apoptosis due to thioridazine. Thioridazine induced the downregulation of c-FLIP(L) and $\mathrm{Mcl}-1$ expressions at the post-translational levels via the upregulation of proteasome activity and decreased Akt phosphorylation. In addition, thioridazine increased intracellular ROS production, which is associated with the induction of proteasome activity and inhibition of Akt signaling. Therefore, our results suggest that thioridazine increased TRAIL-mediated apoptosis via the ROS-mediated inhibition of Akt signaling and downregulation of $\mathrm{Mcl}-1$ and c-FLIP(L) (Figure 6d). These findings support that thioridazine could be an attractive drug for TRAIL sensitization.

Thioridazine is well known to exert anticancer effects via the inhibition of the PI3K/Akt singling pathway. ${ }^{5,6}$ Previous studies reported that $\mathrm{PI} / \mathrm{K} / \mathrm{Akt}$ activation protected human leukemia HL60 cells from TRAIL-mediated apoptosis, ${ }^{26}$ and the inhibition of PI3K/Akt augmented TRAIL sensitization in human leukemia, ${ }^{27}$ neuroblastoma, ${ }^{28}$ and colon cancer cells. ${ }^{29}$ In our study, thioridazine also inhibited Akt phosphorylation (Figure 5a). Previous studies reported that the $\mathrm{PI} 3 \mathrm{~K} /$ Akt signaling pathway is associated with c-FLIP $(\mathrm{L})$ and $\mathrm{Mcl}-1$ expression in murine $\mathrm{B}$ lymphocytes and ovarian cancer cells, respectively. ${ }^{30,31}$ In addition, PI3K/Akt modulates c-FLIP $(\mathrm{L})$ and $\mathrm{Mcl}-1$ protein stability. Moumen et al. ${ }^{32}$ reported that $\mathrm{PI} / \mathrm{K} /$ Akt maintains $\mathrm{c}-\mathrm{FLIP}(\mathrm{L})$ protein stability via 
a

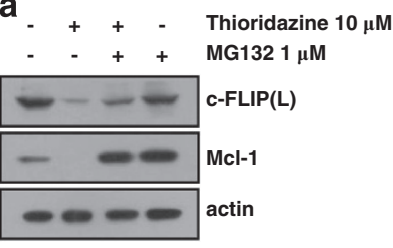

C
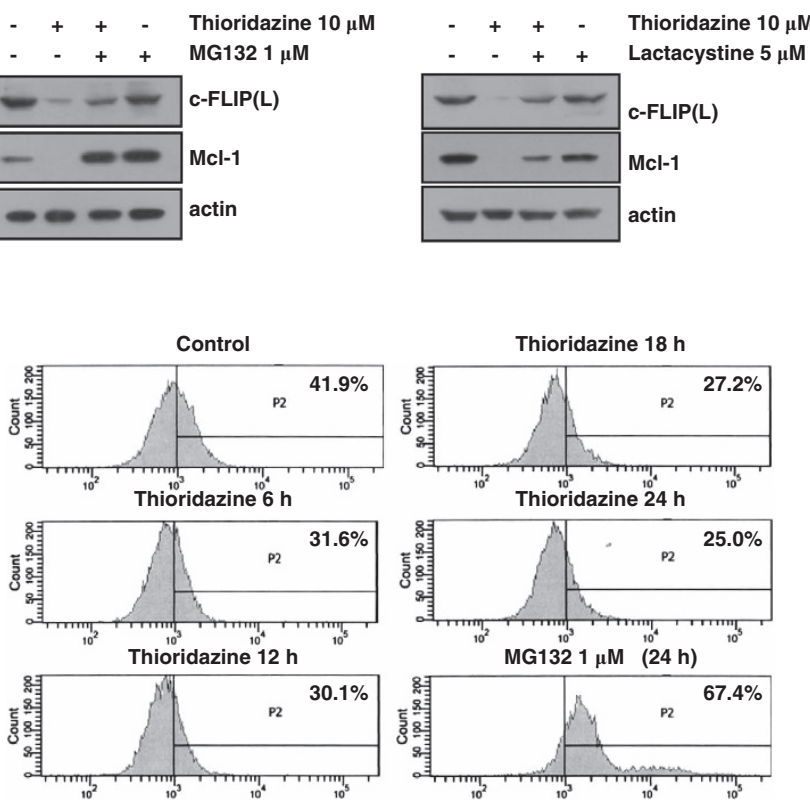
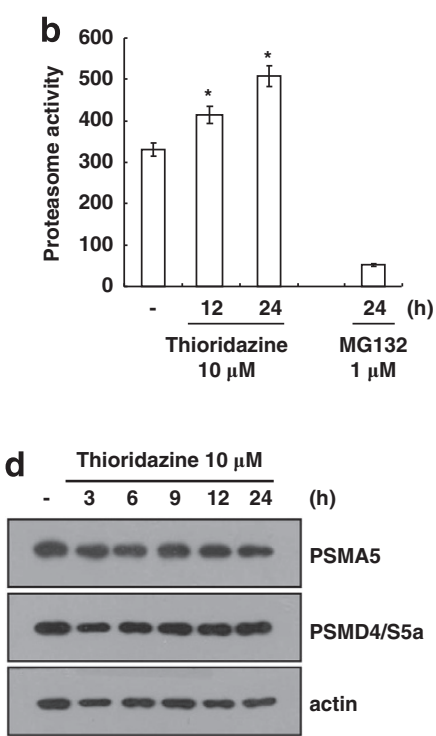
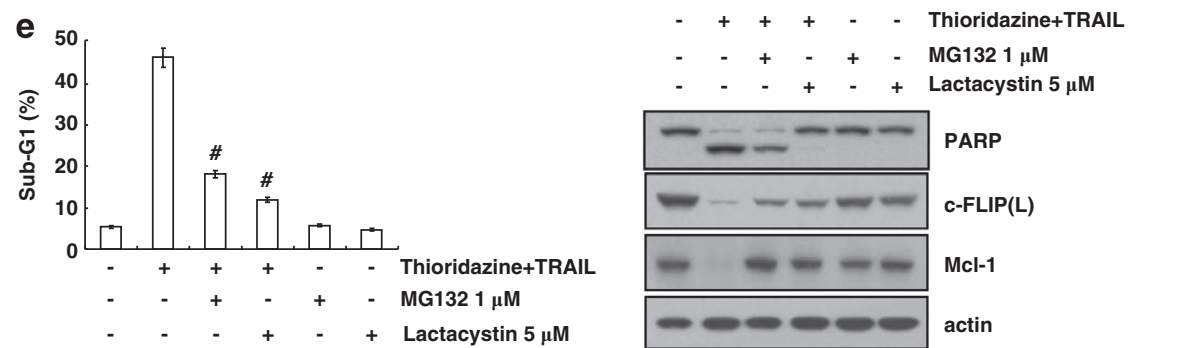

Figure 4 Thioridazine increases the proteasome activity. (a) Caki cells were pretreated with $1 \mu \mathrm{M} M \mathrm{MG} 132$ or $5 \mu \mathrm{M}$ lactacystin for 30 min and then treated with $10 \mu \mathrm{M}$ thioridazine for $24 \mathrm{~h}$. (b) Caki cells were treated with $10 \mu \mathrm{M}$ thioridazine or MG132 (as a positive control) for the indicated time periods. The cells were lysed, and the proteasome activity was measured as described in the Materials and Methods section. (c) Caki cells were transfected with proteasome sensor vector (ZsProSensor-1) and treated with $10 \mu \mathrm{M}$ thioridazine or MG132 (as a positive control) for the indicated time periods. The proteasome activity was analyzed using FACS. (d) Caki cells were treated with $10 \mu \mathrm{M}$ thioridazine for the indicated time periods. The protein expression levels of PSMA5, PSMD4/S5a, and actin were determined by western blotting. The level of actin was used as a loading control. (e) Caki cells were pretreated with $1 \mu \mathrm{M}$ MG132 or $5 \mu \mathrm{M}$ lactacystin for 30 min and then treated with $10 \mu \mathrm{M}$ thioridazine and $50 \mathrm{ng} / \mathrm{ml}$ TRAlL for $24 \mathrm{~h}$. The level of apoptosis was analyzed by measuring the sub-G1 fraction by flow cytometry (left panel). The protein expression levels of PARP, c-FLIP(L), Mcl-1, and actin were determined by western blotting. The level of actin was used as a loading control. The values in (b and $\mathbf{e})$ represent the mean \pm S.D. from three independent samples. ${ }^{\star} P<0.001$ compared with control. ${ }^{\#} P<0.001$ compared with thioridazine plus TRAlL. The data represent three independent experiments

Met signaling in hepatocytes, and granulocyte-macrophage colony-stimulating factor enhances Mcl-1 stability via the activation of PI3K/Akt in neutrophils. ${ }^{33}$ However, other PI3K/ Akt inhibitors (LY294002 and wortmannin) did not affect or downregulate c-FLIP(L) and Mcl-1 expression (Figure 5a) or the induction of proteasome activity (data not shown). The thioridazine-mediated downregulation of c-FLIP $(\mathrm{L})$ and $\mathrm{Mcl}-1$ expression is probably independent of PI3K/Akt signaling in human renal carcinoma Caki cells (Figure 5). Thus, thioridazine likely acts as a stronger sensitizer than LY294002 and wortmannin (Figure 5b).

ROS are important signaling molecules that modulate cellular responses. Thioridazine markedly increased ROS production (Figure 6a), and ROS was associated with thioridazine plus TRAIL-mediated apoptosis (Figure 6b). Furthermore, we detected that ROS modulated the downregulation of $c-F L I P(L)$ and $\mathrm{Mcl}-1$ expression (Figure $6 b$ ). According to previous reports, ROS have dual positive and negative functions on proteasome activity. In neutrophils and hepatocytes, ROS inhibited proteasome activity. ${ }^{34,35}$ In contrast, ROS increased proteasome activity in skeletal muscle myotubes and lens epithelial cells. ${ }^{36,37}$ In our study, the induction of proteasome activity by thioridazine depended on ROS production, and ROS scavengers reversed thioridazine-mediated $\mathrm{C}-\mathrm{FLIP}(\mathrm{L})$ and $\mathrm{Mcl}-1$ downregulation (Figure 6b). However, the mechanism by which thioridazine modulates proteasome activity is unclear. We examined the effect of thioridazine on the protein expression of two critical proteasome subunits: PSMA5 and PSMD4/S5a. ${ }^{23}$ However, thioridazine did not alter either protein (Figure 4d). Therefore, the mechanism by which thioridazine modulates proteasome activity requires further evaluation.

Taken together, our results suggest that thioridazine sensitizes cancer cells, but not normal cells, to TRAILmediated apoptosis via the ROS-mediated inhibition of Akt signaling and downregulation of c-FLIP(L) and $\mathrm{Mcl}-1$ 
a

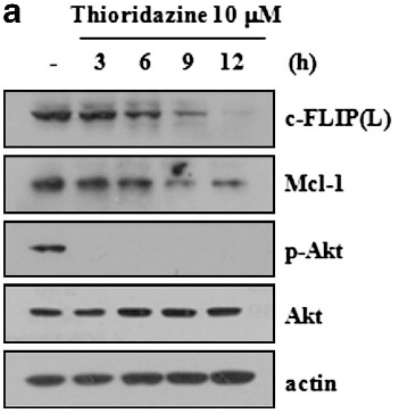

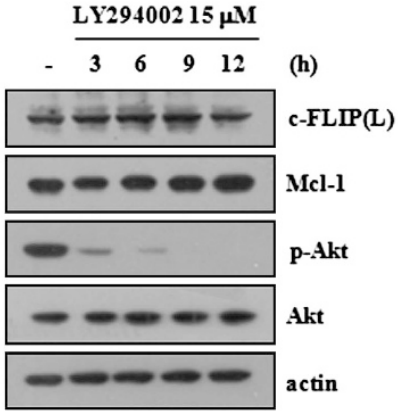

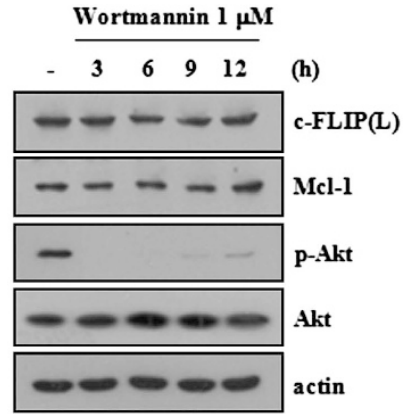

b

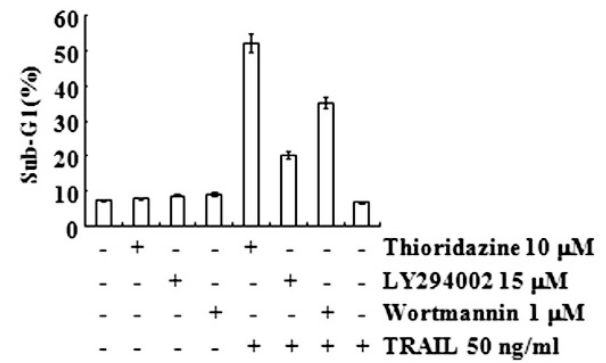

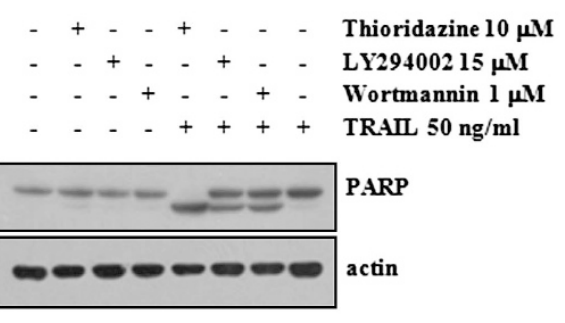

Figure 5 Inhibition of Akt signaling by thioridazine is associated with induction of TRAIL-mediated apoptosis. (a) Caki cells were treated with $10 \mu \mathrm{M}$ thioridazine (left panel), $15 \mu \mathrm{M} \mathrm{LY} 294002$ (middle panel), and $1 \mu \mathrm{M}$ wortmannin (right panel) for the indicated time periods. (b) Caki cells were treated with $50 \mathrm{ng} / \mathrm{ml}$ TRAlL in the presence or absence of $10 \mu \mathrm{M}$ thioridazine, $15 \mu \mathrm{M} \mathrm{LY} 294002$, and $1 \mu \mathrm{M}$ wortmannin for $24 \mathrm{~h}$. The protein expression levels of PARP, c-FLIP(L), Mcl-1, phospho (p)-Akt, Akt, and actin were determined by western blotting. The level of actin was used as a loading control (a and $\mathbf{b})$. The level of apoptosis was analyzed by the sub-G1 fraction using flow cytometry (b). The values represent the mean \pm S.D. from three independent samples. The data represent three independent experiments

expression at the post-translational levels. Therefore, the antipsychotic agent thioridazine may potentially be used to overcome TRAIL resistance in cancer cells.

\section{Materials and Methods}

Cells and materials. Caki, ACHN, A498, MDA-MB231, and U251MG cells were purchased from the American Type Culture Collection (Manassas, VA USA). The mouse kidney cells (TMCK-1) were a gift from Dr. T.J. Lee (Yeungnam University, Korea). A primary culture of human mesangial cells (Cryo NHMC) was purchased from Clonetics (San Diego, CA, USA). The cells were cultured in Dulbecco's modified Eagle medium that contained 10\% fetal bovine serum, $20 \mathrm{mM}$ Hepes buffer, and $100 \mu \mathrm{g} / \mathrm{ml}$ gentamicin. The PCR primers were obtained from Macrogen Inc. (Seoul, Korea), and the other chemicals were obtained from Sigma (St. Louis, MO, USA). NAC and Trolox were obtained from Calbiochem (San Diego, CA, USA). The anti-DR5, anti-Bcl-2, anti$\mathrm{BCl}-\mathrm{xL}$, anti-Mcl-1, anti-XIAP, and anti-PARP antibodies were obtained from Santa Cruz Biotechnology (Santa Cruz, CA, USA). The anti-procaspase-3 and anticleaved caspase-3 antibody was obtained from Cell Signaling Technology (Beverly, MA, USA). The anti-FADD antibody was obtained from BD Bioscience (San Jose, CA, USA). The anti-c-FLIP(L) antibody was obtained from the ALEXIS Corporation (San Diego, CA, USA). The anti-Bim antibody was obtained from Millipore Corporation (Billerica, MA, USA). The anti-actin antibody was obtained from Sigma. The recombinant human TRAIL was obtained from KOMA Biotech (Seoul, Korea).

Western blot analysis. For the western blotting experiments, the cells were washed with cold phosphate-buffered saline (PBS) and lysed on ice in modified RIPA buffer $(50 \mathrm{mM}$ Tris- $\mathrm{HCl}$, pH 7.4, 1\% NP-40, $0.25 \%$ Na-deoxycholate, $150 \mathrm{mM} \mathrm{NaCl}$ $1 \mathrm{mM} \mathrm{Na}_{3} \mathrm{VO}_{4}$, and $1 \mathrm{mM} \mathrm{NaF}$ ) containing protease inhibitors $(100 \mu \mathrm{M}$ phenylmethylsulfonyl fluoride, $10 \mu \mathrm{g} / \mathrm{ml}$ leupeptin, $10 \mu \mathrm{g} / \mathrm{ml}$ pepstatin, and $2 \mathrm{mM}$ EDTA). The lysates were centrifuged at $10000 \times g$ for $10 \mathrm{~min}$ at $4{ }^{\circ} \mathrm{C}$, and the supernatant fractions were collected. The proteins were separated by SDS-PAGE electrophoresis and transferred to Immobilon-P membranes (Millipore Corporation, Billerica, MA, USA). The specific proteins were detected using an enhanced chemiluminescence western blotting kit according to the manufacturer's instructions.
Flow cytometry analysis. For flow cytometry, the cells were resuspended in $100 \mu \mathrm{l}$ of PBS, and $200 \mu \mathrm{l}$ of $95 \%$ ethanol was added while the cells were being vortexed. The cells were then incubated at $4^{\circ} \mathrm{C}$ for $1 \mathrm{~h}$, washed with PBS, resuspended in $250 \mu \mathrm{l}$ of $1.12 \%$ sodium citrate buffer ( $\mathrm{pH} 8.4$ ) with $12.5 \mu \mathrm{g}$ of RNase, and incubated for an additional $30 \mathrm{~min}$ at $37^{\circ} \mathrm{C}$. The cellular DNA was then stained by adding $250 \mu \mathrm{l}$ of a propidium iodide solution $(50 \mu \mathrm{g} / \mathrm{ml})$ to the cells for $30 \mathrm{~min}$ at room temperature. The stained cells were analyzed by fluorescenceactivated cell sorting on a FACScan flow cytometer (Becton Dickinson and Co., Franklin Lakes, NY, USA) to determine the relative DNA content, which was based on the red fluorescence intensity.

\section{$4^{\prime}, 6^{\prime}$-Diamidino-2-phenylindole staining for nuclei condensation} and fragmentation. To examine cellular nuclei, the cells were fixed with $1 \%$ paraformaldehyde on glass slides for $30 \mathrm{~min}$ at room temperature. After fixation, the cells were washed with PBS and a $300 \mathrm{nM} \mathrm{4} 4^{\prime}, 6^{\prime}$-diamidino-2-phenylindole solution (Roche, Mannheim, Germany) was added to the fixed cells for $5 \mathrm{~min}$. After the nuclei were stained, the cells were examined by fluorescence microscopy.

The DNA fragmentation assay. The cell death detection ELISA plus kit (Boerhringer Mannheim; Indianapolis, IN, USA) was used to determine the level of apoptosis by detecting fragmented DNA within the nuclei of thioridazine-treated cells, TRAll-treated cells, or cells that had been treated with a combination of thioridazine and TRAIL. Briefly, each culture plate was centrifuged for $10 \mathrm{~min}$ at $200 \times \mathrm{g}$, the supematant was removed, and the cell pellet was lysed for $30 \mathrm{~min}$. The plate was then centrifuged again at $200 \times g$ for $10 \mathrm{~min}$, and the supernatant that contained the cytoplasmic histone-associated DNA fragments was collected and incubated with an immobilized anti-histone antibody. The reaction products were incubated with a peroxidase substrate for $5 \mathrm{~min}$ and measured by spectrophotometry at $405 \mathrm{~nm}$ and $490 \mathrm{~nm}$ (reference wavelength) with a microplate reader. The signals in the wells containing the substrate alone were subtracted as the background.

Asp-Glu-Val-Asp-ase (DEVDase) activity assay. To evaluate DEVDase activity, cell lysates were prepared after their respective treatments with TRAIL in the presence or absence of thioridazine. Assays were performed in 96-well microtiter plates by incubating $20 \mu \mathrm{g}$ of cell lysates in $100 \mu \mathrm{l}$ of reaction buffer ( $1 \% \mathrm{NP}-40,20 \mathrm{mM}$ Tris- $\mathrm{HCl}, \mathrm{pH} 7.5,137 \mathrm{mM} \mathrm{NaCl}, 10 \%$ glycerol) 
a
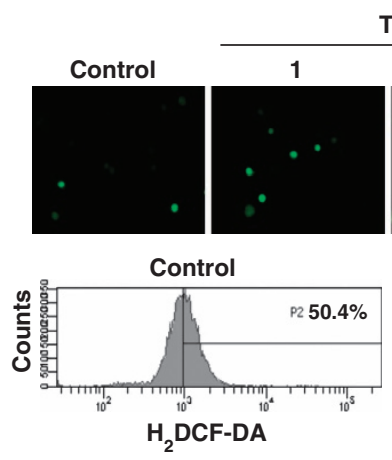

C

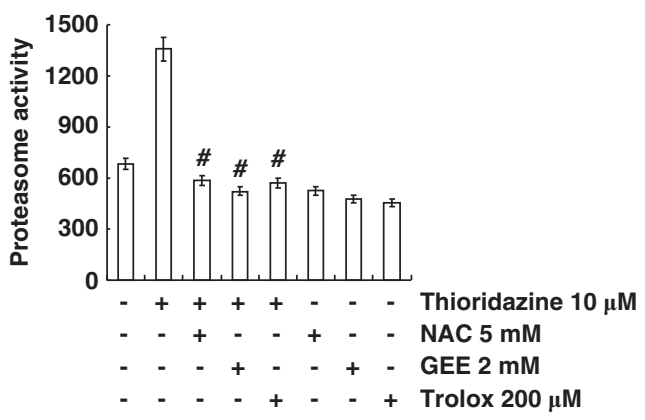

b
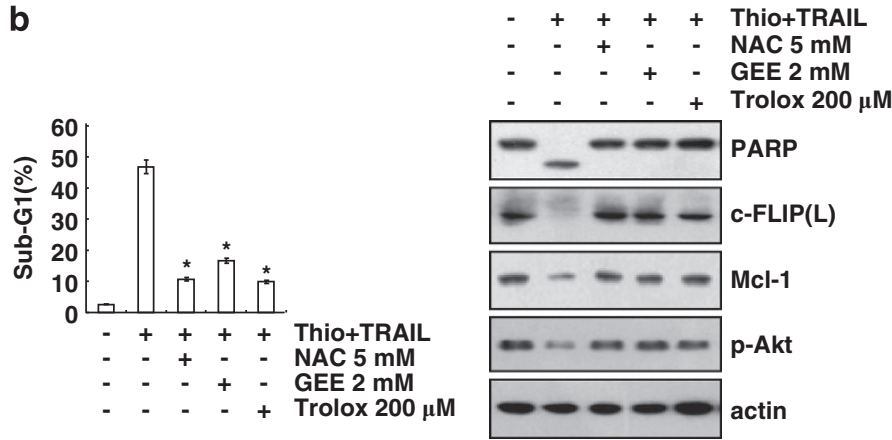

d Thioridazine

$\downarrow$

Intracellular ROS increase

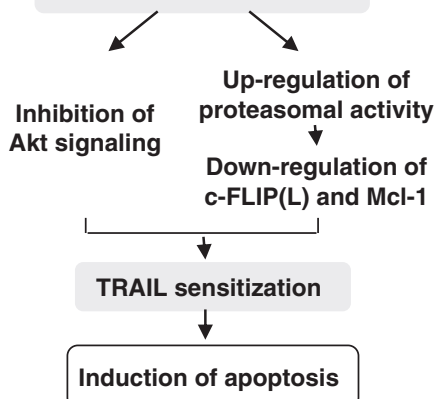

Figure 6 Thioridazine plus TRAIL-induced apoptosis is dependent on ROS generation in Caki cells. (a) Caki cells were treated with the indicated concentrations of thioridazine for $30 \mathrm{~min}$ and loaded with a $\mathrm{H}_{2}$ DCFDA fluorescent dye. $\mathrm{H}_{2}$ DCFDA fluorescence intensity was detected by fluorescence microscopy (upper panel) and flow cytometry (lower panel). (b) Caki cells were pretreated with $5 \mathrm{mM} \mathrm{NAC,} 2 \mathrm{mM} \mathrm{GEE}$, and $200 \mu \mathrm{M}$ trolox for $30 \mathrm{~min}$, and then stimulated with $10 \mu \mathrm{M}$ thioridazine (thio) and $50 \mathrm{ng} /$ $\mathrm{ml}$ TRAIL for $24 \mathrm{~h}$. Apoptosis was analyzed as the sub-G1 population by FACS analysis. The protein expression levels of PARP, c-FLIP(L), Mcl-1, phospho (p)-Akt, and actin were determined by western blotting. The level of actin was used as a loading control. ${ }^{*} P<0.001$ compared with thioridazine plus TRAIL. (c) Caki cells were pretreated with $5 \mathrm{mM}$ NAC, $2 \mathrm{mM}$ GEE, $200 \mu \mathrm{M}$ trolox for $30 \mathrm{~min}$, and then stimulated with $10 \mu \mathrm{M}$ thioridazine for $24 \mathrm{~h}$. The cells were lysed, and proteasome activity was measured as described in the Materials and Methods section. ${ }^{\#} P<0.001$ compared with thioridazine. (d) Models for thioridazine-mediated TRAIL sensitization in Caki cells. Thioridazine triggers intracellular ROS production. Increased ROS inhibit Akt signaling and increase proteasome activity. Upregulation of proteasome activity leads to the downregulation of c-FLIP(L) and Mcl-1 expression at the post-translational levels. Both inhibitions of Akt signaling and upregulation of proteasome activity are associated with induction of TRAILmediated apoptosis in thioridazine-treated Caki cells

containing a caspase substrate (Asp-Glu-Val-Asp-chromophore-p-nitroanilide (DVAD-pNA)) at $5 \mu \mathrm{M}$. Lysates were incubated at $37^{\circ} \mathrm{C}$ for $2 \mathrm{~h}$. Thereafter, the absorbance at $405 \mathrm{~nm}$ was measured with a spectrophotometer.

Reverse transcription polymerase chain reaction. Total RNA was isolated using the TriZol reagent (Life Technologies; Gaithersburg, MD, USA), and the CDNA was prepared using M-MLV reverse transcriptase (Gibco-BRL; Gaithersburg, MD, USA) according to the manufacturers' instructions. The following primers were used for the amplification of human $c-F L I P(L), M c l-1$, and actin: c-FLIP(L) (sense) $5^{\prime}$-CGGACTATAGAGTGCTGATGG- $3^{\prime}$ and (antisense) 5'-GATTATCAGGCAGATTCCTAG-3', Mcl-1 (sense) 5'-GCGACTGGCAAAGCT TGGCCTCAA- $3^{\prime}$ and (antisense) $5^{\prime}$-GTTACAGCTTGGATCCCAACTGCA-3', and actin (sense) $5^{\prime}$-GGCATCGTCACCAACTGGGAC-3' and (antisense) $5^{\prime}$-CGAT TTCCCGCTCGGCCGTGG-3'. The PCR amplification was carried out using the following cycling conditions: $94^{\circ} \mathrm{C}$ for 3 min followed by 17 (actin) or 23 cycles (c-FLIP(L), and Mcl-1) of $94^{\circ} \mathrm{C}$ for $45 \mathrm{~s}, 58^{\circ} \mathrm{C}$ for $45 \mathrm{~s}, 72^{\circ} \mathrm{C}$ for $1 \mathrm{~min}$, and a final extension at $72{ }^{\circ} \mathrm{C}$ for $10 \mathrm{~min}$. The amplified products were separated by electrophoresis on a 1.5\% agarose gel and detected under UV light.

Mcl-1 and c-FLIP(L) constructs and stable cell. The human Mcl-1 and $\mathrm{c}-\mathrm{FLIP}(\mathrm{L})$ expression vectors were constructed, as described previously. . $^{38,39}$ The Caki cells were transfected in a stable manner with the pFLAG-CMV-4/Mcl-1 or pcDNA 3.1-c-FLIP(L) plasmid using LipofectAMINE (Invitrogen, Carlsbad, CA, USA), as prescribed by the manufacturer. After $48 \mathrm{~h}$ of incubation, transfected cells were selected in cell culture medium containing $700 \mu \mathrm{g} / \mathrm{ml} \mathrm{G418} \mathrm{(Invitrogen).}$ After 2 or 3 weeks, single independent clones were randomly isolated, and each individual clone was plated separately. After clonal expansion, cells from each independent clone were tested for Mcl-1 or c-FLIP(L) expression by immunoblotting and were used in this study.

Proteasome activity assay. The chymotryptic proteasome activities were measured with Suc-LLVY-AMC (chymotryptic substrate, Biomol International, Plymouth Meeting, PA, USA). The cells were collected, washed with PBS, and lysed. A mixture containing $1 \mu \mathrm{g}$ protein of the cell lysate in $100 \mathrm{mM}$ Tris- $\mathrm{HCl}(\mathrm{pH}$ 8.0), $10 \mathrm{mM} \mathrm{MgCl}_{2}$, and $2 \mathrm{mM} \mathrm{ATP}$ was incubated at $37^{\circ} \mathrm{C}$ for 30 min with $50 \mu \mathrm{M}$ Suc-LLVY-AMC. The enzyme activity was measured with a fluorometric plate reader at an excitation wavelength of $380 \mathrm{~nm}$ and an emission wavelength of $440 \mathrm{~nm}$. The measurement of proteasome activity within cells was determined using ZsGreen (proteasome sensor vector)-transfected stable Caki cell lines (BD Biosciences). ZsGreen fused with a destabilization sequence subjected to rapid ubiquitination and degradation by proteasome in mouse ornithine decarboxylase. Fluorescence was detected using a fluorescence microscope and FACS Canto ${ }^{\mathrm{TM}}$ (BD Biosciences).

Measurement of ROS. The intracellular accumulation of ROS was determined using the fluorescent probes $2^{\prime}, 7^{\prime}$-dichlorodihydrofluorescein diacetate ( $\mathrm{H}_{2}$ DCFDA). $\mathrm{H}_{2}$ DCFDA is commonly used to measure ROS generation. ${ }^{40}$ Caki cells were pretreated with $5 \mathrm{mM} \mathrm{NAC}, 2 \mathrm{mM} \mathrm{GEE}$, and $200 \mu \mathrm{M}$ trolox for $30 \mathrm{~min}$, 
and the cells were then incubated in $10 \mu \mathrm{M}$ thioridazine for $30 \mathrm{~min}$. The cells were stained with the fluorescent dye $\mathrm{H}_{2} \mathrm{DCFDA}$ for an additional $10 \mathrm{~min}$. The cells were then trypsinized and resuspended in PBS, and fluorescence was measured at specific time intervals with a flow cytometer (Becton-Dickinson, Franklin Lakes, NJ, USA) or detected by using a fluorescence microscope (Zeiss, Goettingen, Germany).

Densitometry. The band intensities were scanned and quantified using the gel analysis plugin for the open source software ImageJ 1.46 (Imaging Processing and Analysis in Java; ttp://rsb.info.nih.gov/ij).

Statistical analysis. The data were analyzed using a one-way ANOVA and post-hoc comparisons (Student-Newman-Keuls) using the Statistical Package for Social Sciences 8.0 software (SPSS Inc., Chicago, IL, USA).

\section{Conflict of Interest}

The authors declare no conflict of interest.

Acknowledgements. This work was supported by the Mid-Career Researcher Program through an NRF grant funded by the MEST (No. 2011. 0016239), an NRF grant funded by the Korea Government (MSIP) (2013 041811), Ministry of Science, ICT \& Future Planning (2012M3A9B 6055414), and Keimyung Basic Medical Research Promoting Grant launched from 2012.

1. Realmuto GM, Erickson WD, Yellin AM, Hopwood JH, Greenberg LM. Clinical comparison of thiothixene and thioridazine in schizophrenic adolescents. Am J Psychiatry 1984; 141: 440-442.

2. Ohman R, Axelsson R. Relationship between prolactin response and antipsychotic effect of thioridazine in psychiatric patients. Eur J Clin Pharmacol 1978; 14: 111-116.

3. Bettencourt MV, Bosne-David S, Amaral L. Comparative in vitro activity of phenothiazines against multidrug-resistant Mycobacterium tuberculosis. Int J Antimicrob Agents 2000; 16 69-71

4. van Soolingen D, Hernandez-Pando R, Orozco H, Aguilar D, Magis-Escurra C, Amaral L et al. The antipsychotic thioridazine shows promising therapeutic activity in a mouse model of multidrug-resistant tuberculosis. PLoS One 2010; 5.

5. Kang S, Dong SM, Kim BR, Park MS, Trink B, Byun HJ et al. Thioridazine induces apoptosis by targeting the PI3K/Akt/mTOR pathway in cervical and endometrial cancer cells. Apoptosis 2012; 17: 989-997.

6. Rho SB, Kim BR, Kang S. A gene signature-based approach identifies thioridazine as an inhibitor of phosphatidylinositol-3'-kinase (PI3K)/AKT pathway in ovarian cancer cells. Gynecol Oncol 2011; 120: 121-127.

7. Nagel D, Spranger S, Vincendeau M, Grau M, Raffegerst S, Kloo B et al. Pharmacologic inhibition of MALT1 protease by phenothiazines as a therapeutic approach for the treatment of aggressive ABC-DLBCL. Cancer Cell 2012; 22: 825-837.

8. Gil-Ad I, Shtaif B, Levkovitz Y, Dayag M, Zeldich E, Weizman A. Characterization of phenothiazine-induced apoptosis in neuroblastoma and glioma cell lines: clinical relevance and possible application for brain-derived tumors. J Mol Neurosci 2004; 22 189-198.

9. Zhelev Z, Ohba H, Bakalova R, Hadjimitova V, Ishikawa M, Shinohara Y et al. Phenothiazines suppress proliferation and induce apoptosis in cultured leukemic cells without any influence on the viability of normal lymphocytes. Phenothiazines and leukemia. Cancer Chemother Pharmacol 2004; 53: 267-275.

10. Gil-Ad I, Shtaif B, Levkovitz Y, Nordenberg J, Taler M, Korov I et al. Phenothiazines induce apoptosis in a B16 mouse melanoma cell line and attenuate in vivo melanoma tumo growth. Oncol Rep 2006; 15: 107-112.

11. Buckley NA, Whyte IM, Dawson AH. Cardiotoxicity more common in thioridazine overdose than with other neuroleptics. J Toxicol Clin Toxicol 1995; 33: 199-204.

12. Dallaire S. Thioridazine (Mellaril) and mesoridazine (Serentil): prolongation of the QTc interval. CMAJ 2001; 164: 91-95.

13. Ashkenazi A, Pai RC, Fong S, Leung S, Lawrence DA, Marsters SA et al. Safety and antitumor activity of recombinant soluble Apo2 ligand. J Clin Invest 1999; 104: 155-162.

14. Leverkus M, Neumann M, Mengling T, Rauch CT, Brocker EB, Krammer PH et al. Regulation of tumor necrosis factor-related apoptosis-inducing ligand sensitivity in primary and transformed human keratinocytes. Cancer Res 2000; 60: 553-559.

15. Wiley SR, Schooley K, Smolak PJ, Din WS, Huang CP, Nicholl JK et al. Identification and characterization of a new member of the TNF family that induces apoptosis. Immunity 1995; 3: 673-682

16. Jin Z, McDonald ER 3rd, Dicker DT, El-Deiry WS. Deficient tumor necrosis factor-related apoptosis-inducing ligand (TRAIL) death receptor transport to the cell surface in human colon cancer cells selected for resistance to TRAIL-induced apoptosis. J Biol Chem 2004; 279: 35829-35839.
17. Kelly MM, Hoel BD, Voelkel-Johnson C. Doxorubicin pretreatment sensitizes prostate cancer cell lines to TRAIL-induced apoptosis which correlates with the loss of c-FLIP expression. Cancer Biol Ther 2002; 1: 520-527.

18. Ng CP, Zisman A, Bonavida B. Synergy is achieved by complementation with Apo2L/TRAIL and actinomycin D in Apo2L/TRAIL-mediated apoptosis of prostate cancer cells: role of XIAP in resistance. Prostate 2002; 53: 286-299.

19. Walczak H, Bouchon A, Stahl H, Krammer PH. Tumor necrosis factor-related apoptosisinducing ligand retains its apoptosis-inducing capacity on $\mathrm{Bcl}-2$ - or $\mathrm{Bcl}-\mathrm{xL}-$-overexpressing chemotherapy-resistant tumor cells. Cancer Res 2000; 60: 3051-3057.

20. Zhang $Y$, Zhang B. TRAIL resistance of breast cancer cells is associated with constitutive endocytosis of death receptors 4 and 5 . Mol Cancer Res 2008; 6: 1861-1871.

21. Fukazawa T, Fujiwara T, Uno F, Teraishi F, Kadowaki Y, Itoshima T et al. Accelerated degradation of cellular FLIP protein through the ubiquitin-proteasome pathway in p53-mediated apoptosis of human cancer cells. Oncogene 2001; 20: 5225-5231.

22. Zhong Q, Gao W, Du F, Wang X. Mule/ARF-BP1, a BH3-only E3 ubiquitin ligase, catalyzes the polyubiquitination of Mcl-1 and regulates apoptosis. Cell 2005; 121: 1085-1095.

23. Groll M, Huber R. Substrate access and processing by the $20 \mathrm{~S}$ proteasome core particle. Int J Biochem Cell Biol 2003; 35: 606-616.

24. Dhaunsi GS, Singh B, Singh AK, Kirschner DA, Singh I. Thioridazine induces lipid peroxidation in myelin of rat brain. Neuropharmacology 1993; 32: 157-167.

25. Rodrigues T, Santos AC, Pigoso AA, Mingatto FE, Uyemura SA, Curti C. Thioridazine interacts with the membrane of mitochondria acquiring antioxidant activity toward apoptosis_-potentially implicated mechanisms. Br J Pharmacol 2002; 136: 136-142.

26. Bortul R, Tazzari PL, Cappellini A, Tabellini G, Billi AM, Bareggi R et al. Constitutively active Akt1 protects HL60 leukemia cells from TRAlL-induced apoptosis through a mechanism involving NF-kappaB activation and cFLIP(L) up-regulation. Leukemia 2003; 17: 379-389.

27. Martelli AM, Tazzari PL, Tabellini G, Bortul R, Billi AM, Manzoli L et al. A new selective AKT pharmacological inhibitor reduces resistance to chemotherapeutic drugs, TRAIL, all-trans-retinoic acid, and ionizing radiation of human leukemia cells. Leukemia 2003; 17: 1794-1805.

28. Kim S, Kang J, Qiao J, Thomas RP, Evers BM, Chung DH. Phosphatidylinositol 3-kinase inhibition down-regulates survivin and facilitates TRAIL-mediated apoptosis in neuroblastomas. J Pediatr Surg 2004; 39: 516-521.

29. Rychahou PG, Murillo CA, Evers BM. Targeted RNA interference of PI3K pathway components sensitizes colon cancer cells to TNF-related apoptosis-inducing ligand (TRAIL). Surgery 2005; 138: 391-397.

30. Chen C, Chang YC, Lan MS, Breslin M. Leptin stimulates ovarian cancer cell growth and inhibits apoptosis by increasing cyclin D1 and Mcl-1 expression via the activation of the MEK/ERK1/2 and PI3K/Akt signaling pathways. Int J Oncol 2013; 42: 1113-1119.

31. Moriyama H, Yonehara S. Rapid up-regulation of c-FLIP expression by BCR signaling through the PI3K/Akt pathway inhibits simultaneously induced Fas-mediated apoptosis in murine B lymphocytes. Immunol Lett 2007; 109: 36-46.

32. Moumen A, leraci A, Patane S, Sole C, Comella JX, Dono R et al. Met signals hepatocyte survival by preventing Fas-triggered FLIP degradation in a PI3k-Akt-dependent manner. Hepatology 2007; 45: 1210-1217.

33. Derouet M, Thomas L, Cross A, Moots RJ, Edwards SW. Granulocyte macrophage colony-stimulating factor signaling and proteasome inhibition delay neutrophil apoptosis by increasing the stability of Mcl-1. J Biol Chem 2004; 279: 26915-26921.

34. Zmijewski JW, Zhao X, Xu Z, Abraham E. Exposure to hydrogen peroxide diminishes NF-kappaB activation, IkappaB-alpha degradation, and proteasome activity in neutrophils. Am J Physiol Cell Physiol 2007; 293: C255-C266

35. Ishihara Y, Takeuchi K, Ito F, Shimamoto N. Dual regulation of hepatocyte apoptosis by reactive oxygen species: increases in transcriptional expression and decreases in proteasomal degradation of BimEL. J Cell Physiol 2011; 226: 1007-1016.

36. Li YP, Chen Y, Li AS, Reid MB. Hydrogen peroxide stimulates ubiquitin-conjugating activity and expression of genes for specific E2 and E3 proteins in skeletal muscle myotubes. $\mathrm{Am} \mathrm{J}$ Physiol Cell Physiol 2003; 285: C806-C812.

37. Shang F, Gong X, Taylor A. Activity of ubiquitin-dependent pathway in response to oxidative stress. Ubiquitin-activating enzyme is transiently up-regulated. J Biol Chem 1997; 272: 23086-23093.

38. Um HJ, Kwon TK. Protective effect of melatonin on oxaliplatin-induced apoptosis through sustained Mcl-1 expression and anti-oxidant action in renal carcinoma Caki cells. J Pineal Res 2010; 49: 283-290.

39. Kim S, Lee TJ, Leem J, Choi KS, Park JW, Kwon TK. Sanguinarine-induced apoptosis: generation of ROS, down-regulation of Bcl-2, c-FLIP, and synergy with TRAIL. J Cell Biochem 2008; 104: 895-907.

40. LeBel CP, Ischiropoulos H, Bondy SC. Evaluation of the probe 2',7'-dichlorofluorescin as an indicator of reactive oxygen species formation and oxidative stress. Chem Res Toxicol 1992; 5: 227-231.

(c) (1) () Cell Death and Disease is an open-access journal published by Nature Publishing Group. This work is licensed under a Creative Commons Attribution-NonCommercialNoDerivs 3.0 Unported License. To view a copy of this license, visit http://creativecommons.org/licenses/by-nc-nd/3.0/ 